\title{
Self-sensitized photochlorination of benzo[a]pyrene in saline water under simulated solar light irradiation
}

\author{
Mina Yang ${ }^{a}$, Haijing Zhang ${ }^{b}$, Fei Chang ${ }^{c}$, Xuefeng $\mathrm{Hu}^{\text {a, b,* }}$ \\ ${ }^{a}$ School of Environmental Science and Engineering, Shaanxi University of Science and Technology, Xi'an 710021, PR China \\ ${ }^{\mathrm{b}}$ Key Laboratory of Coastal Environmental Processes and Ecological Remediation, Yantai Institute of Coastal Zone Research, Chinese Academy of Sciences, Yantai, \\ 264003 Shandong, PR China \\ ${ }^{\mathrm{c}}$ School of Environment and Architecture, University of Shanghai for Science and Technology, Shanghai 200093, PR China
}

\section{A R T I C L E I N F O}

Editor: Dr. L. Angela Yu-Chen

\section{Keywords:}

Photochlorination

Benzo[a]Pyrene

Self-sensitized

Saline water

Solar light

\begin{abstract}
A B S T R A C T
Chlorinated organic compounds are ubiquitously detected in saline waters. The photochlorination of organic compounds is one possible source, and chlorine radicals originating from other photosensitive substances have been reported to be responsible for organic compounds chlorination in previous reports. In this study, benzo[ $a$ ] pyrene $(\mathrm{BaP})$ chlorination in $10 \%$ acetonitrile/ $\mathrm{NaCl}$ aqueous solution was initiated by self-sensitization of $\mathrm{BaP}$, while chlorine radicals were not involved in the reaction. After $45 \mathrm{~min}$ of photoreaction in four seawater samples, chlorinated product (6-ClBaP) accounted for 10-17\% of the fraction of transformed BaP, which was higher than that previously reported. The influences of $\mathrm{Cl}^{-}, \mathrm{pH}$, humic acid, electron donors, and particulate matter on the formation of chlorobenzo[a]pyrene were systematically investigated. A self-sensitized photochlorination reaction mechanism was proposed as follow: photoexited BaP was activated to singlet state and then transformed to triplet state through inter-system crossing. Then the excited triplet state and oxygen formed $\left[{ }^{3} \mathrm{BaP}^{*}{ }^{3} \mathrm{O}_{2}\right]$ or $\left[\mathrm{BaP}-{ }^{1} \mathrm{O}_{2}\right]$ complex, which further reacted with $\mathrm{Cl}^{-}$to produce 6-ClBaP.
\end{abstract}

\section{Introduction}

Many of polycyclic aromatic hydrocarbons (PAHs) are ubiquitous carcinogens and mutagens formed by natural diagenetic or anthropogenic processes. PAHs can enter environmental waters through industrial and municipal wastewater, runoff or rainwater (Mai et al., 2018; Zhang et al., 2012; Lawal, 2017; Yang et al., 2020). As a typical member of PAHs, benzo[a]pyrene (BaP) can absorb surface solar radiation, which enables its photodegradation in natural waters (Kot-Wasik et al., 2004; Xia et al., 2009). The photodegradation intermediates of $\mathrm{BaP}$ in both pure and natural waters have been studied for many years, and the detected intermediates are mainly dione, monohydroxy and catechol derivatives of $\mathrm{BaP}$, as reported in previous works (Luo et al., 2019; Sanches et al., 2011; Del Carlo et al., 2012).

Chlorinated polycyclic aromatic hydrocarbons (ClPAHs) are a class of halogenated aromatic hydrocarbons (HAHs) that are ubiquitous environmental contaminants. The chlorination of PAHs is expected to increase the stability of these compounds in the environment (Ohura et al., 2008). ClPAHs have lower vapor pressures and higher octanol-water partition coefficients $\left(\log \mathrm{K}_{\mathrm{ow}}\right.$ ) and exhibit stronger mutagenicity than their parent PAHs (Ohura, 2007; Sun et al., 2013). ClPAHs have been found in air, automobile exhaust, tap water, waste and sediments (Sun et al., 2013). They might be produced by the chlorine disinfection of water and the combustion of chlorine-containing materials. Recently, Shinohara et al. investigated the concentrations of PAHs and ClPAHs in the sediments of some tidal flats and found that ClPAHs exhibited a significant positive correlation with the salinity, but no such correlation was observed for PAHs (Sankoda et al., 2012, 2013). They proposed that the photochemical reaction of PAHs might be a potential source of ClPAHs in tidal flats. In their lab-scale experiments, ClPAH formation was observed on surface of glass beads in aqueous $\mathrm{NaCl}$ solutions under UV light irradiation (Sankoda et al., 2012, 2013). Despite the widespread occurrence of ClPAHs in the environment, the chlorination mechanism has not been well understood to date.

Natural seawater is particularly rich in chloride ions, which greatly influence the transformation of various species in an aqueous environment under irradiation. To organic compounds that can not absorb solar light, chlorine radicals originating from other photosensitive substances are likely responsible for their chlorination (Vione et al., 2005; Wu and $\mathrm{Hu}, 2012$; Hu et al., 2015). Our previous work investigated the

\footnotetext{
* Corresponding author at: School of Environmental Science and Engineering, Shaanxi University of Science and Technology, Xi'an 710021, PR China.

E-mail address: huxuefeng@sust.edu.cn (X. Hu).
} 
photoreaction of aniline in aqueous solutions containing $\mathrm{Ag}^{+} / \mathrm{Fe}^{3+}$ and $\mathrm{Cl}^{-}$under simulated sunlight irradiation (Wu and $\mathrm{Hu}, 2012$; Hu et al., 2015), where chlorine radicals originating from the photolysis of $\mathrm{Ag}-\mathrm{Cl} / \mathrm{Fe}-\mathrm{Cl}$ complex were responsible for aniline chlorination. No chloroaniline was detectable in the absence of $\mathrm{Ag}^{+} / \mathrm{Fe}^{3+}$ because aniline and $\mathrm{Cl}^{-}$are unable to absorb solar light effectively. Photoinduced holes and $\bullet \mathrm{OH}$ drove the oxidation of $\mathrm{Cl}^{-}$to $\mathrm{Cl} \bullet / \mathrm{Cl}_{2}^{--}$radicals, and thus promoted the chlorination of aniline (Vione et al., 2005; Hu et al., 2015). Aromatic ketones were reported to form charge transfer complexes with halides (exciplexes), producing reactive halogen radicals by charge separation (Parker and Mitch, 2016). Regarding PAHs, Shinohara et al. tried the photochlorination of anthracene on the surface of glass beads in aqueous $\mathrm{NaCl}$ solutions under UV light irradiation (Sankoda et al., 2012) and proposed that chlorination was probably triggered by photochemically produced anthracene cation radicals and/or chloride radicals.

Benzo $[a]$ pyrene $(\mathrm{BaP})$ is a typical high molecular weight PAH with five rings and is one of the most carcinogenic PAHs. It has been classified by the US Environmental Protection Agency (US EPA) as a priority pollutant and is the most studied compound in the PAH class (Juhasz and Naidu, 2000). Due to its multiple aromatic ring system, BaP can absorb sunlight in the visible and ultraviolet regions of the solar spectrum (290-900 nm), resulting in its structure modification (Teranishi et al., 2010). Photochlorination of BaP in acid brine solutions was observed before, and chloride radicals initiated by excited states of BaP were proposed to involve in the chlorination mechanism (Ohura and Miwa, 2016). This mechanism is only suitable for acid brine solutions. However, saline water in nature (seawater and saline lakes) is typically neutral to alkaline, the $\mathrm{pH}$ of Lonar lake is even up to 10.5 (Tambekar et al., 2013). In this paper, BaP was used as a model compound to research the photochlorination of PAHs in alkaline saline water under simulated solar light irradiation. The influences of environmental factors $\left(\mathrm{Cl}^{-}\right.$concentration, $\mathrm{pH}$, humic acid concentration, electron donors, and particulate matter) on the formation of chlorobenzo $[a]$ pyrene were systematically investigated, by which a general photochlorination reaction pathway was eventually proposed.

\section{Material and methods}

\subsection{Materials and reagents}

Benzo $[a]$ pyrene $(>99 \%)$, propylene carbonate (>99.5\%), Nchlorosuccinimide (>97\%), methanol (>99.9\%), acetonitrile (> 99.9\%) and 3-amino-2,2,5,5-tetramethyl-1-pyrrolidinyloxy (3ap, $>99 \%$ ) were purchased from J\&K Chemical Ltd. (Beijing, China). Potassium ferrocyanide (AR) was purchased from Linzi Tiande Institute of Fine Chemicals (Zibo,China). $\mathrm{NaCl}(\geq 99.5 \%)$ and $\mathrm{HClO}_{4}(70-72 \%)$ were purchased from Sinopharm Chemical Reagents Co. Ltd. (Shanghai, China). Humic acid (fulvic acid $\geq 90 \%$, HA) was purchased from Aladdin Chemistry Co. Ltd. (Shanghai, China). Potassium iodide (AR) and ferric oxide (AR) were purchased from Kermel Chemical Reagents Co. Ltd. (Tianjin, China). Nano-titanium dioxide (Rutile, $60 \mathrm{~nm}$, $>$ 99.8\%) was purchased from Gracia Chengdu Chemical Technology Co., Ltd. (Chengdu, China). Aluminum oxide (neutral) was purchased from Shanghai Wusi Chemical Reagents Co. Ltd. (Shanghai, China). Sodium hydroxide (AR) was purchased from Tianjin Tianda Chemical Reagents Co. Ltd. (Tianjin,China).

Benzo $[a]$ pyrene stock solution $\left(5 \times 10^{-4} \mathrm{~mol} / \mathrm{L}\right)$ was prepared in acetonitrile and stored in the refrigerator at $4{ }^{\circ} \mathrm{C}$. Reaction solutions were prepared daily by diluting the stock solution with acetonitrile and deionized water just before use unless especially stated otherwise. The ratio of organic solvent and water was 1:10, and the solution pHs were adjusted to 10.3 by $\mathrm{NaOH}$ solution. Seawater samples were collected from Bohai Bay and filtered through $0.45 \mu \mathrm{m}$ glass fiber filters. The seawater reaction solutions were prepared by adding BaP stock solution and acetonitrile to seawater samples without $\mathrm{pH}$ adjusting, the resulting ratio of acetonitrile and seawater was 1:9.

\subsection{Synthesis of 6-chlorobenzo[a]pyrene}

$\mathrm{N}$-Chlorosuccinimide $(130 \mathrm{mg}$ ) was added to benzo[a]pyrene (250 $\mathrm{mg})$ in propylene carbonate $(10 \mathrm{~mL})$. The mixture was maintained at $100^{\circ} \mathrm{C}$ for $2 \mathrm{~h}$, and then water $(10 \mathrm{~mL})$ was added to precipitate the solid (Dewhurst and Kitchen, 1972). The solid product was dissolved in acetonitrile, and a small amount of benzene was added. The mixture solution was separated by HPLC and then subjected to rotary evaporation for enrichment to give 6-chlorobenzo[a]pyrene (6-ClBaP). ${ }^{1} \mathrm{H}$ NMR $\left(500 \mathrm{MHz}, \mathrm{CDCl}_{3}\right) \delta$ (ppm): 9.10-9.04 (2H, m, H10 + H11), 8.88-8.43 $(1 \mathrm{H}, \mathrm{m}, \mathrm{H} 7), 8.56(1 \mathrm{H}, \mathrm{d}, J=9.45 \mathrm{~Hz}, \mathrm{H} 5), 8.34(1 \mathrm{H}, \mathrm{d}, J=9.1 \mathrm{~Hz}$, H12), 8.27 (1H, d, $J=7.65 \mathrm{~Hz}, \mathrm{H} 1), 8.14(1 \mathrm{H}, \mathrm{d}, J=7.25 \mathrm{~Hz}, \mathrm{H} 3$ ), $8.05(1 \mathrm{H}, \mathrm{d}, J=9.45 \mathrm{~Hz}, \mathrm{H} 4), 8.01(1 \mathrm{H}, \mathrm{t}, J=7.6,7.55 \mathrm{~Hz}, \mathrm{H} 2)$, 7.92-7.87 (2 H, m, H8 +H9).<smiles></smiles>

\subsection{Experimental methods}

The light-irradiation device used was $300 \mathrm{~W}$ Xe lamp (CEL-HXF300, Beijing Aulight Co. Ltd.) equipped with a cut off filter ( $>290 \mathrm{~nm}$ ). The irradiation of aqueous solutions $(40 \mathrm{~mL}$ ) was carried out in quartz glass reacting cells $(4.0 \mathrm{~cm}$ diameter and $7.5 \mathrm{~cm}$ height), which were positioned at a distance of $11 \mathrm{~cm}$ to the lamp center. The light intensity was $50 \mathrm{~mW} / \mathrm{cm}^{2}$, and the ambient temperature was $\sim 20^{\circ} \mathrm{C}$. The deaerated experiment was done under $\mathrm{N}_{2}$ atmosphere by deaeration of test solution using $\mathrm{N}_{2}$. For the solid particles experiments, solid particles was added the solution and stirred in dark for $1 \mathrm{~h}$ to reach an adsorption-desorption equilibration of $\mathrm{BaP}$ onto surface of solid particles before irradiation. After irradiation, $5 \mathrm{~mL}$ aliquots were sampled and centrifuged to dislodge suspended solid particles. The obtained solid particles was ultrasonic extracted three times with $5 \mathrm{~mL} \mathrm{CH} \mathrm{Cl}_{2}$. The combined four parts solutions were concentrated in room temperature and then diluted with acetonitrile to a final volume of $1 \mathrm{~mL}$ for analysis. To get rid of water in solutions, methanol was added during rotary evaporation. Concentration of $\mathrm{BaP}$ and $6-\mathrm{ClBaP}$ in solid particlescontaining system was calculated using the sum of $\mathrm{BaP}$ and 6-ClBaP in solutions and adsorbed on solid particles.

The solutions were analyzed by High-performance liquid chromatography (HPLC) (Waters, Milford, MA) consisting of a Waters 2695 Separations Module, a Waters 2998 photodiode array detector and a Waters SunFire C18 column $(4.6 \times 250 \mathrm{~mm}, 5.0 \mathrm{~mm})$. A mixture of acetonitrile and water $(90 / 10$, vol/vol) was used as the mobile phase at a constant flow of $1.2 \mathrm{~mL} \mathrm{~min}^{-1}$. The injection volume was $25 \mu \mathrm{L}$. 6chlorobenzo[a]pyrene was compared with the synthesis reagents and quantified at its maximum absorption. A DB-5MS capillary column with a $0.25 \mathrm{~mm}$ ID $\times 30 \mathrm{~m}$ length, $0.25 \mu \mathrm{m}$ film (Agilent Technologies, Inc) was used for the gas chromatography (GC Agilent Technologies 7890A) and MSD (Agilent Technologies 5975C) analysis with helium at $1 \mathrm{~mL}$ $\min ^{-1}$ as the carrier gas. Detection was performed by the selective ion monitoring (SIM) mode or by full scanning. The initial temperature of $50{ }^{\circ} \mathrm{C}$ was maintained for $2 \mathrm{~min}$, raised at a rate of $8{ }^{\circ} \mathrm{C} \mathrm{min}^{-1}$ to $150{ }^{\circ} \mathrm{C}$ and maintained for $3 \mathrm{~min}$ then followed by $3{ }^{\circ} \mathrm{C} \min ^{-1}$ to $300{ }^{\circ} \mathrm{C}$ and maintained for $10 \mathrm{~min}$. The detector temperature was $300^{\circ} \mathrm{C}$.

A nanosecond laser flash photolysis spectrometer (LF900, Edinburgh Instruments Ltd) was used to carry out Laser flash photolysis (LFP) experiments. A Nd: YAG pulse laser $(355 \mathrm{~nm})$ with a pulse duration of $6 \mathrm{~ns}$ 
was used as the excitation light source. The impulse voltage was $1.15 \mathrm{kV}$. Experiments were performed in $1 \mathrm{~cm}$ quartz cells.

\section{Results and discussion}

\subsection{Photochlorination of $\mathrm{BaP}$ in $\mathrm{a} \mathrm{Cl}^{-}$-containing aqueous solution under simulated solar light irradiation}

As shown in Fig. 1, 6-ClBaP formed in $\mathrm{Cl}^{-}$-containing aqueous solutions of $\mathrm{BaP}$ under simulated solar light irradiation. The concentration of 6-ClBaP increased rapidly in the first hour of irradiation and then slowly increased for $1-3 \mathrm{~h}$ to a maximum. The formation of 6-ClBaP was positively correlated with the $\mathrm{NaCl}$ concentration. When the concentrations of $\mathrm{Cl}^{-}$were $0.002,0.004,0.02$ and $0.1 \mathrm{M}$, the 6-ClBaP yields were $0.084 \%, 0.23 \%, 0.90 \%$ and $1.46 \%$, respectively, after $1 \mathrm{~h}$ of photoreaction. The degradation percentage of $\mathrm{BaP}$ decreased, and the 6$\mathrm{ClBaP}$ formation amount increased after $5 \mathrm{~h}$ of photoreaction when the $\mathrm{BaP}$ concentration was increased from 1 to $10 \mu \mathrm{M}$ at a constant $\mathrm{Cl}^{-}$ concentration of $0.02 \mathrm{M}$ (Fig. S1). BaP $(1 \mu \mathrm{M})$ and its chlorinated products were completely degraded after $3 \mathrm{~h}$ of photoreaction. In these reaction systems, BaP was the only substance that can absorb simulated solar light and initiate the photoreaction. Excited states of BaP should play major roles during photochlorination process.

\subsection{Effects of $p H$}

In previous studies, the amount of chlorinated products formed correlated with the amount of chlorine radicals generated and with the rates of the reactions between the organic compounds and chlorine radicals at different $\mathrm{pH}$ values. In Fe-containing saline water, a low $\mathrm{pH}$ facilitated the formation of chlorine radicals under photoirradiation, resulting in the production of more chlorinated product (Liu et al., 2009; $\mathrm{Wu}$ and $\mathrm{Hu}, 2012$ ). In an $\mathrm{AgCl}$ particle system, the formation of chlorine radicals was independent of the $\mathrm{pH}$ (Hu et al., 2015). The amount of chlorinated product formed increased with decreasing $\mathrm{pH}$ because the reaction rates between the chlorine radicals and various organic compounds increased at lower $\mathrm{pH}$ values (Remucal and Manley, 2016). Ohura and Miwa reported the formation of 6-ClBaP at $\mathrm{pH} 2$ and 3 but not at $\mathrm{pH} 4$ and 5 in $\mathrm{Cl}^{-}$-containing solutions under visible light irradiation (Ohura and Miwa, 2016). They proposed that the excited states of BaP initiated the generation of superoxide and hydroxyl radicals $\left(\mathrm{O}_{2}^{--}\right.$and $\bullet \mathrm{OH})$, then $\bullet \mathrm{OH}$ reacted with $\mathrm{Cl}^{-}$resulting in the formation of $\mathrm{HOCl}^{-} \bullet$. Dissociation of $\mathrm{HOCl}^{-}$under acidic conditions provided $\mathrm{Cl} \bullet$, which reacted with $\mathrm{BaP}$ to produce 6 - $\mathrm{ClBaP}$. The photochlorination mechanism of $\mathrm{BaP}$ in base solution is not clear but should be different from the acid solution. Here, as shown in Fig. 2A, an increase in the $\mathrm{pH}$ from 2.2 to 10.3 led to a decrease in the degradation rate of $\mathrm{BaP}$ and an increase in the amount of 6 -ClBaP formed. Formation of $6-\mathrm{ClBaP}$ at $\mathrm{pH} 4.3$ was

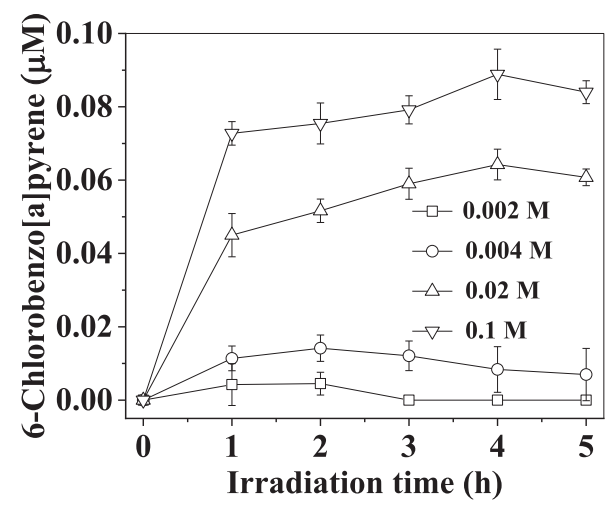

Fig. 1. Formation of $6-\mathrm{ClBaP}$ at different $\mathrm{Cl}^{-}$concentrations in $10 \%$ acetonitrile/aqueous solution under different irradiation time. $5 \mu \mathrm{M} \mathrm{BaP}, \mathrm{pH} 10.3$. different from the previous results (Ohura and Miwa, 2016), the lower $\mathrm{Cl}^{-}$concentration $(1.28 \mathrm{mM}$ ) and different light source (mercury lamp) used in that study may responsible for the absence of 6-ClBaP. To better understand the formation mechanism of 6-ClBaP in alkaline solution, a high $\mathrm{pH}$ of 10.3 was used in subsequent experiments. Under simulated solar irradiation, BaP can be excited to a singlet state and rapidly undergo intersystem crossing to the excited triplet state (Fasnacht and Blough, 2002). The excited BaP transfers electrons or energy to $\mathrm{O}_{2}$, resulting in the formation of $\mathrm{BaP}$ radical cations and reactive oxygen species (ROS). Thus, ROS, excited states and radical cations of BaP are possible reactive species in the formation of 6-ClBaP. Three main initial pathways, which involve radical cations, singlet oxygen and hydroxyl radicals, have been reported for the degradation of PAHs (Abdulazeez and Lawal, 2017). For these three pathways, the degradation rate in alkaline solutions is slower than that in acidic or neutral solutions, and the main degradation intermediates are dione products, as previously reported (Kot-Wasik, 2004). The higher concentration of 6-ClBaP observed in this study indicated that a different pathway might be involved in its formation.

\subsection{Effects of solid particles}

PAHs tend to be associated with suspended particulate materials because of their hydrophobicity. Mineral particles $\left(\mathrm{SiO}_{2}, \mathrm{Al}_{2} \mathrm{O}_{3}, \mathrm{TiO}_{2}\right.$, etc.) are ubiquitous in surface water. Photodegradation of organic compounds by semiconductor $\mathrm{TiO}_{2}$ is well known, and the degradation rates of $\mathrm{BaP}$ enhanced evidently in the presence of $\mathrm{TiO}_{2}$ as shown in Fig. $3 \mathrm{~A}$. $\mathrm{Al}_{2} \mathrm{O}_{3}$ and $\mathrm{SiO}_{2}$ can initiate the degradation reaction via electron transfer from adsorbed organic compounds to solid particles (Karunakaran et al., 2011). It was reported that the photolysis of adsorbed PAHs occurs mainly through two mechanisms: a singlet oxygen-mediated pathway and a radical intermediate pathway (Fioressi and Arce, 2003, 2005). Under irradiation, PAHs adsorbed on $\mathrm{Al}_{2} \mathrm{O}_{3}$ and $\mathrm{SiO}_{2}$ surfaces produce radical cations, which further react with water to produce stable photoproducts. PAHs radical cations might originate from an excited singlet state, not the triplet state. Diones, diols, and monohydroxy derivatives were found to be the major photoproducts of PAHs adsorbed on silica gel and alumina surfaces (Fioressi and Arce, 2005). In this study, BaP photodegradation increased in the presence of all three solid particles. However, the formation of 6-ClBaP decreased in the following order: $\mathrm{SiO}_{2}>\mathrm{Al}_{2} \mathrm{O}_{3}>\mathrm{TiO}_{2}$ (Fig. 3). The increased degradation rate should be related to the ROS oxidation and/or the radical cation intermediate of $\mathrm{BaP}$, leading to the formation of photoproducts such as diones, diols, and monohydroxy derivatives. These reaction pathways compete with the chlorination pathway and increase the degradation of $6-\mathrm{ClBaP}$, which result in a reduction of $6-\mathrm{ClBaP}$ concentration in solutions.

\subsection{Roles of ROS}

No significant decrease of $\mathrm{BaP}$ and 6-ClBaP formation is observed in dark as shown in Fig. S2 and Fig. 4 respectively. The formation of 6ClBaP was completely inhibited in a $\mathrm{N}_{2}$ atmosphere, which suggested that $\mathrm{O}_{2} / \mathrm{ROS}$ played important roles in the chlorination of BaP. To determine the roles of ROS in the formation of 6-ClBaP, several ROS initiators and scavengers were added to the reaction solutions. The reaction rate constant of hydroxyl radical with benzo[a]pyrene is $0.94 \times 10^{9} \mathrm{M}^{-1} \mathrm{~s}^{-1}$ (Jin et al., 2012), and rate constant of hydroxyl radicals reaction with acetonitrile is $2.12 \times 10^{6}$ (Anbar et al., 1966). Concentration of $\mathrm{BaP}$ and acetonitrile in the reaction solution are $5 \times 10^{-6} \mathrm{M}$ and $1.91 \mathrm{M}$, respectively. Then the reaction rate of acetonitrile with hydroxyl radicals is about 1000 times higher than that of BaP with hydroxyl radicals. Consequently, the exact role of radicals in these reactions cannot be interpreted well due to the high potential for near-complete radical scavenging by our matrix and should be further investigated for reasonable description. The results indicated that 

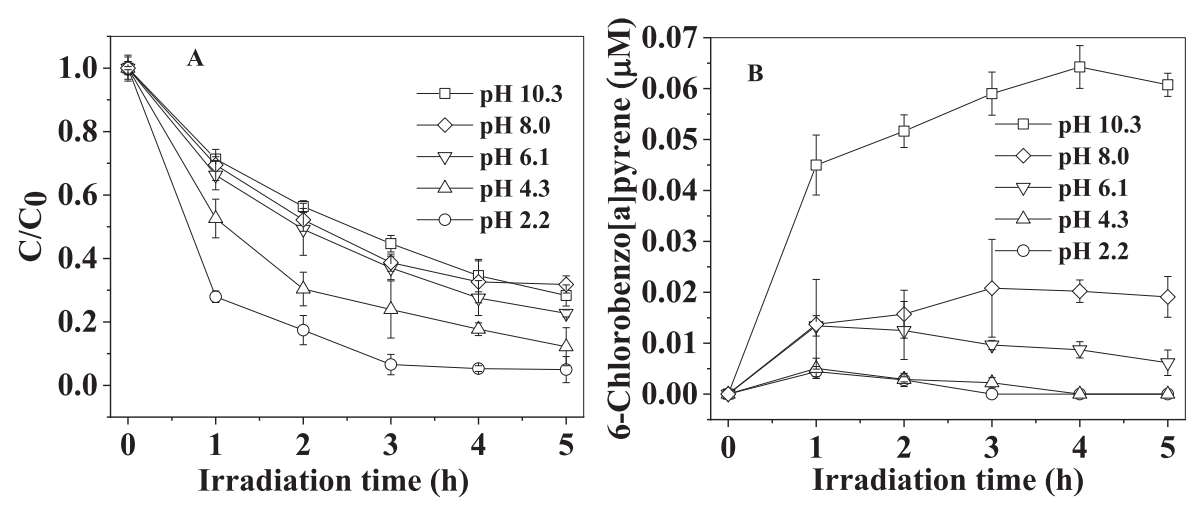

Fig. 2. (A) Degradation of $\mathrm{BaP}$ and (B) formation of $6-\mathrm{ClBaP}$ in $10 \%$ acetonitrile/aqueous solution at different $\mathrm{pH}$ values under different irradiation time. $5 \mu \mathrm{M}$ BaP, $0.02 \mathrm{M} \mathrm{Cl}^{-}$.
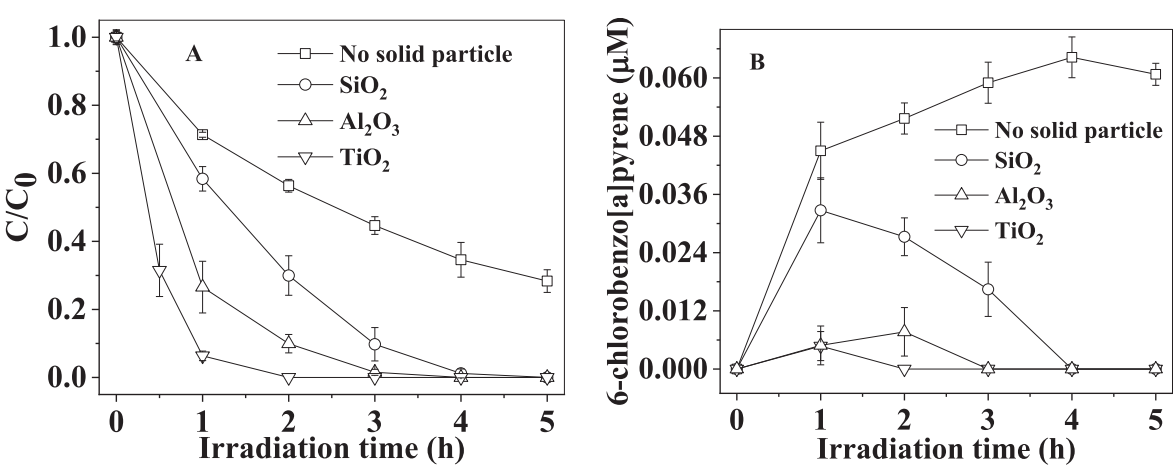

Fig. 3. (A) Degradation of $\mathrm{BaP}$ and (B) formation of $6-\mathrm{ClBaP}$ in the presence of different solid particles in $10 \%$ acetonitrile/aqueous solution under different irradiation time. $5 \mu \mathrm{M} \mathrm{BaP}, 0.02 \mathrm{M} \mathrm{Cl}^{-}, 0.2 \mathrm{~g} / \mathrm{L}$ solid particles, $\mathrm{pH} 10.3$.

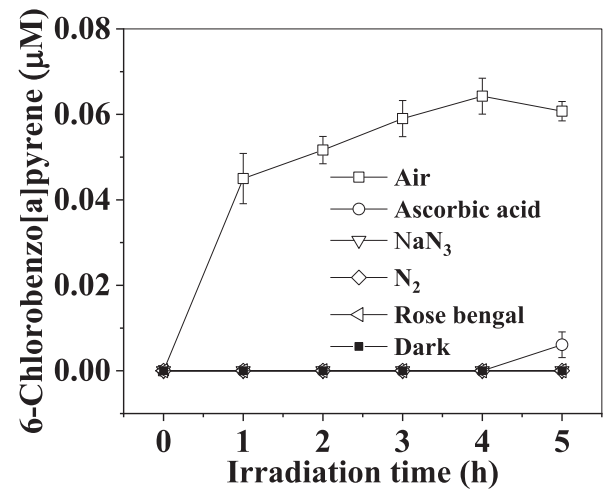

Fig. 4. Effects of ROS and light on 6-ClBaP formation in 10\% acetonitrile/ aqueous solution under different irradiation time. $5 \mu \mathrm{M} \mathrm{BaP}, 0.02 \mathrm{M} \mathrm{Cl}^{-}$, $100 \mathrm{mg} / \mathrm{L}$ ascorbic acid, $100 \mathrm{mg} / \mathrm{L} \mathrm{NaN}_{3}, 20 \mu \mathrm{M}$ rose bengal (irradiated with $\lambda>420 \mathrm{~nm}$; visible light was used to excite rose bengal to generate singlet oxygen), $\mathrm{pH} 10.3$.

hydroxyl radicals exerted no significant effects on the degradation of $\mathrm{BaP}$ and formation of 6-ClBaP. We previously reported that $\mathrm{Cl}_{2}^{--}$might be involved in the chlorination of aniline (Wu and Hu, 2012). However, no chlorinated aniline was detectable when aniline was added to the BaP photochlorination system. In addition, the $\mathrm{Cl}_{2}^{\circ-}$ signal at $340 \mathrm{~nm}$ was not observable by laser flash photolysis (LFP) (Liu et al., 2009). These results excluded the possibility of BaP chlorination by $\mathrm{Cl}_{2}^{\circ-}$, which was formed by reaction with $\bullet \mathrm{OH}$ or oxidation of other reactive species. The addition of $\mathrm{NaN}_{3}$ and ascorbic acid as scavengers of singlet oxygen completely suppressed the formation of 6 -ClBaP. Therefore, it was confirmed that the chlorination reaction of $\mathrm{BaP}$ involves singlet oxygen. The addition of humic acid (HA) resulted in the acceleration of BaP degradation, but a reduction in 6-ClBaP formation (Fig. S3). It seems to be related to $\mathrm{HA}$ as inner filter reduces the production of excited BaP, while it enhances the formation of singlet oxygen (Wang et al., 2015). Rose bengal, an initiator of singlet oxygen, was added to the reaction solution, which was irradiated with visible light $(\lambda>420 \mathrm{~nm})$ to ensure that only rose bengal was excited. The UV-vis absorption spectrum of BaP is below $420 \mathrm{~nm}$ as shown in Fig. S4. In this case, no 6-ClBaP formation was observed, although the produced singlet oxygen effectively degraded BaP. It seems that only if $\mathrm{BaP}$ is excited and singlet oxygen generated together resulting in the formation of 6-ClBaP.

Singlet oxygen has a longer lifetime in $\mathrm{D}_{2} \mathrm{O}$ than in water, the products formation route related to singlet oxygen should increase when $\mathrm{H}_{2} \mathrm{O}$ is replaced by $\mathrm{D}_{2} \mathrm{O}$. However, $\mathrm{D}_{2} \mathrm{O}$ exhibits stronger hydrogen bonds than $\mathrm{H}_{2} \mathrm{O}$, which slow the reaction rate of water-involved reaction, such as $\mathrm{BaP}$ radical cations reaction with water to produce photoproducts (Fioressi and Arce, 2005). As shown in Fig. 5, $\mathrm{D}_{2} \mathrm{O}$ slowed down the degradation of $\mathrm{BaP}$, whereas the formation of 6-ClBaP increased. $\mathrm{D}_{2} \mathrm{O}$ inhibit the water-involved reaction and resulting in the decreased $\mathrm{BaP}$ degradation rate. Singlet oxygen is an important factor in $\mathrm{BaP}$ degradation in this reaction system, the addition of ascorbic acid and $\mathrm{NaN}_{3}$ as scavengers of singlet oxygen significantly suppressed BaP degradation (Fig. S2) and formation of 6-ClBaP (Fig. 4). Enhanced singlet oxygen lifetime in $\mathrm{D}_{2} \mathrm{O}$ was beneficial for 6-ClBaP formation but not for the degradation of $\mathrm{BaP}$, which indicating that singlet oxygen involved in BaP chlorination in another way but not oxidation directly. These results suggested that singlet oxygen reacted with BaP via two pathways: (1) the direct oxidation of $\mathrm{BaP}$ and (2) reaction with $\mathrm{Cl}^{-}$and $\mathrm{BaP}$ excited states, resulting in the formation of 6-ClBaP. All the $\mathrm{BaP}$ degradation pathways compete with each other during the photoreaction, and the use of $\mathrm{D}_{2} \mathrm{O}$ in the reaction facilitates the 6-ClBaP formation pathway. 

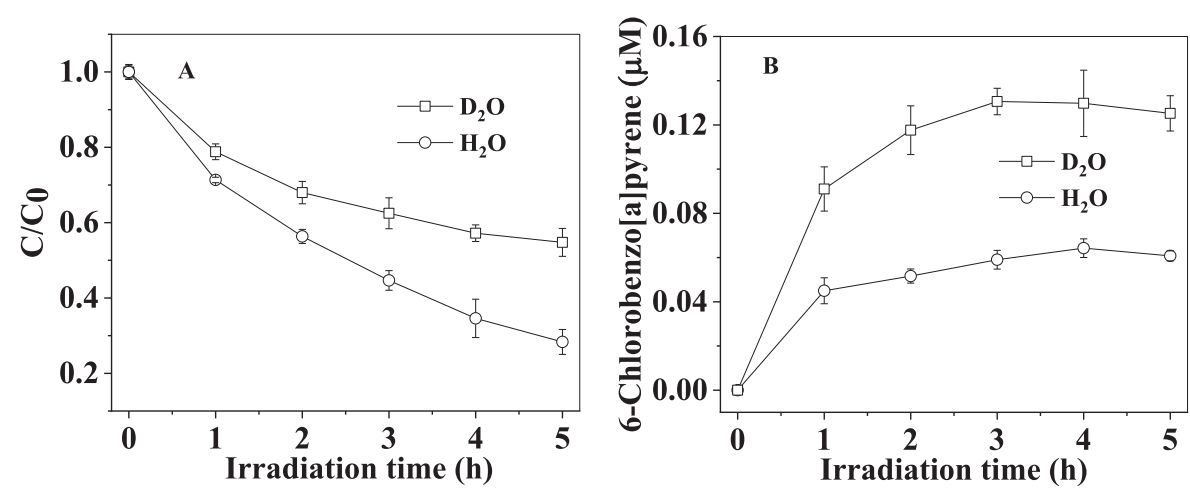

Fig. 5. (A) Degradation of $\mathrm{BaP}$ and (B) formation of 6-ClBaP in $10 \%$ acetonitrile/ $\mathrm{H}_{2} \mathrm{O}$ or $\mathrm{D}_{2} \mathrm{O}$ solution under different irradiation time. $5 \mu \mathrm{M} \mathrm{BaP,} 0.02 \mathrm{M} \mathrm{Cl}{ }^{-}$, $\mathrm{pH} 10.3$.

\subsection{Roles of the active intermediates of BaP formed by photoexcitation}

Upon photoirradiation, BaP can absorb light energy for photoionization or for the formation of photoexcited substances $\left({ }^{1} \mathrm{P}^{*}\right.$ and $\left.{ }^{3} \mathrm{P}^{*}\right)$ and act as a photosensitizer (Stathis, 2018). The photoexcited initiator species can either transfer energy to molecular oxygen to produce singlet oxygen by a type II mechanism or transfer an electron to $\mathrm{O}_{2}$ by type I mechanism. Fig. 4 shows that Type II pathway plays a dominant role, as using ${ }^{1} \mathrm{O}_{2}$ quenchers completely stops 6-ClBaP formation. To directly test if $\mathrm{BaP}^{\bullet+}$ can react with $\mathrm{Cl}^{-}$to form 6-ClBaP, the electron donors 3ap and $\mathrm{KI}$ were added to the reaction solution. It was previously reported that electron donors can effectively reduce $\mathrm{BaP}^{\bullet+}$ to $\mathrm{BaP}$ (Fasnacht and Blough, 2003a), which was benefit for the formation of other BaP excited states. The addition of electron donors increased formation of 6-ClBaP as shown in Fig. S5 indicated that active intermediates of the $\mathrm{BaP}$ excited states other than $\mathrm{BaP}^{\bullet+}$ are responsible for the chlorination of BaP.

Photodegradation of PAHs via the excited singlet state occurs primarily through electron transfer to $\mathrm{O}_{2}$ resulting in the formation of its radical cation, whereas degradation via the triplet state occurs predominately through a direct reaction of $\mathrm{O}_{2}$ with the PAHs within the collision complexes (Fasnacht and Blough, 2003a). Degradation can proceed via reaction with its excited singlet, triplet, or both states. The excited states of $\mathrm{BaP}\left({ }^{1} \mathrm{BaP}^{*}\right.$ and $\left.{ }^{3} \mathrm{BaP}^{*}\right)$ are also possible active intermediates that initiate the chlorination reaction. The direct reaction of $\mathrm{O}_{2}$ with ${ }^{1} \mathrm{BaP}^{*}$ to form products should not occur due to spin restrictions, but the reaction could proceed through a $\left[\mathrm{BaP}^{\bullet+}-\mathrm{O}_{2}^{\bullet-}\right]$ complex. However, the above results indicated that $\mathrm{BaP}^{\bullet+}$ is not the reactive intermediate in 6-ClBaP formation. PAHs photoreactions could also be initiated by the direct reaction of $\mathrm{O}_{2}$ with the excited triplet states of the PAHs, i.e., with ${ }^{3} \mathrm{BaP}^{*}$ in a $\left[{ }^{3} \mathrm{BaP}^{*-}{ }^{3} \mathrm{O}_{2}\right]$ or $\left[\mathrm{BaP}^{-1} \mathrm{O}_{2}\right]$ complex, which is formed by transferring energy from ${ }^{3} \mathrm{BaP}^{*}$ to oxygen within the complex (Fasnacht and Blough, 2003a).

LFP is a useful technique for researching transient species, including radicals and transient states. Aqueous solutions of $\mathrm{BaP}^{\bullet+}$ and ${ }^{3} \mathrm{BaP}^{*}$ exhibited absorption bands at $550 \mathrm{~nm}$ and $465-480 \mathrm{~nm}$, respectively, in LFP transient absorption spectra (Fasnacht and Blough, 2002, 2003a, 2003b). Strong $\mathrm{BaP}^{\bullet+}$ absorbance peaks were observed at $550 \mathrm{~nm}$ when the reaction solution was irradiated with a $355 \mathrm{~nm}$ laser in an air atmosphere, as shown in Fig. 6. This absorbance peak was not observed in an $\mathrm{N}_{2}$ atmosphere, indicating that $\mathrm{BaP}^{\bullet+}$ originated from the transfer of electrons from the excited $\mathrm{BaP}$ to oxygen. An absorbance peak at $470 \mathrm{~nm}$ corresponding to ${ }^{3} \mathrm{BaP} *$ was detected in an $\mathrm{N}_{2}$ atmosphere (similar signal in the presence and absence of $\mathrm{NaCl}$ ). However, this peak was quenched by oxygen in an air atmosphere. At the same time, a new peak appeared at $445 \mathrm{~nm}$, which was tentatively attributed to an excited $\mathrm{BaP}$ and oxygen complex, $\left[{ }^{3} \mathrm{BaP}_{-}{ }^{3} \mathrm{O}_{2}\right]$ or $\left[\mathrm{BaP}_{-}{ }^{1} \mathrm{O}_{2}\right]$, as previously mentioned (Fasnacht and Blough, 2003a). The disappearance of this peak after adding $\mathrm{NaCl}$ suggested that $\mathrm{Cl}^{-}$interacts with the excited

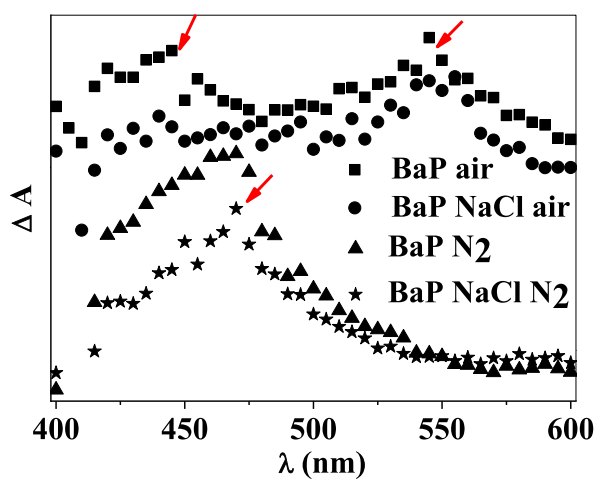

Fig. 6. Transient absorption spectra of $\mathrm{BaP}$ excited at $355 \mathrm{~nm}$ in $10 \%$ acetonitrile/aqueous solution under air and $\mathrm{N}_{2}$ atmospheres. $10^{-3} \mathrm{M} \mathrm{BaP}, 0.02 \mathrm{M}$ $\mathrm{NaCl}, \mathrm{pH} 10.3$.

states. Combined with the earlier analysis, the photoexcitation intermediates of $\mathrm{BaP}$ and singlet oxygen should participate in the chlorination of $\mathrm{BaP}$, and it is reasonable to assume that the corresponding excited state is $\left[\mathrm{BaP}-{ }^{1} \mathrm{O}_{2}\right]$ formed by self-sensitization, which reacts with $\mathrm{Cl}^{-}$to produce 6-ClBaP. It was reported that energy transfer from triplet state of organic photosensitizer to oxygen was found more efficient in basic than in acid medium (Bonneau et al., 1975). Then basic condition facilitated the formation of excited $\mathrm{BaP}$ and oxygen complex $\left[{ }^{3} \mathrm{BaP}^{*}{ }_{-}^{3} \mathrm{O}_{2}\right]$ or $\left[\mathrm{BaP}_{-}{ }^{1} \mathrm{O}_{2}\right]$ and product $6-\mathrm{ClBaP}$. $\left[\mathrm{BaP}-{ }^{1} \mathrm{O}_{2}\right]$ is also a precursor of singlet oxygen, the yield of $\left[\mathrm{BaP}^{-}{ }^{1} \mathrm{O}_{2}\right]$ deactive to singlet oxygen is rather high in a nonpolar solvent (Schweitzer and Schmidt, 2003). In polar solvents (acetonitrile and water), the coupling of $\left[\mathrm{BaP}-{ }^{1} \mathrm{O}_{2}\right.$ ] increases (Schweitzer and Schmidt, 2003), enhancing the formation of $6-\mathrm{ClBaP}$. The formation pathway of $6-\mathrm{ClBaP}$ is shown in Scheme 1.

\subsection{Photochlorination of BaP in seawater under solar light irradiation}

As shown in Fig. 7, the formation of 6-ClBaP in natural seawater sampled from Laizhou Bay under solar light irradiation (average light intensity of $40 \mathrm{~mW} / \mathrm{cm}^{2}$ throughout the experimental period) was observed after adding $5 \mu \mathrm{M} \mathrm{BaP}$ and $10 \%$ acetonitrile. The high $\mathrm{Cl}^{-}$ concentration and low TOC facilitated the formation of 6-ClBaP (the

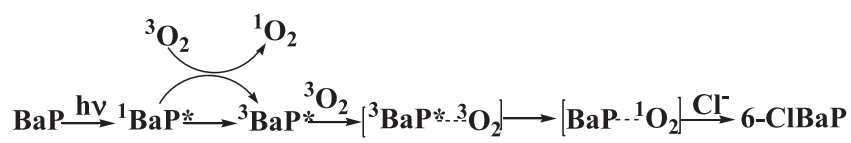

Scheme 1. Formation pathway of $6-\mathrm{ClBaP}$ in $10 \%$ acetonitrile/ $\mathrm{NaCl}$ aqueous solution. 


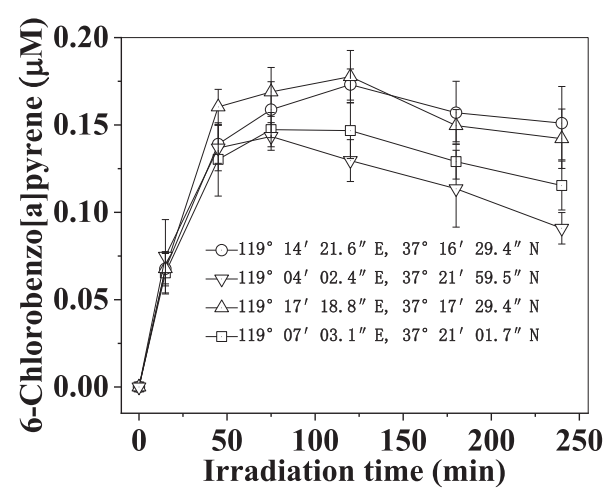

Fig. 7. Time evolution of 6-ClBaP in $10 \%$ acetonitrile/seawater sampled from Laizhou Bay under solar light irradiation. $5 \mu \mathrm{M} \mathrm{BaP}$.

essential information of seawater samples is shown in Table S1), which was consistent with the above results. Formation of 6-ClBaP was promoted in the first $45 \mathrm{~min}$, reaching $0.13-0.16 \mu \mathrm{M}$ before decaying slowly after a period of formation/transformation. Typically, 6-ClBaP accounted for $10-17 \%$ of the fraction of transformed BaP after $45 \mathrm{~min}$ of photoreaction in the four measured samples. The yield of the chlorinated product in this pathway was higher than that in the chlorine radical attack pathway (the yield was less than 1.5\%), as previously reported (Ohura et al., 2008; Hu et al., 2014). The other two products identified by GC-MS were BaP diones, which have been reported by many researchers (Luo et al., 2019; Sanches et al., 2011; Del Carlo et al., 2012).

\section{Conclusion}

Since the constituent of the natural water is complex and different from those used in the mechanistic studies, as such the ClBaP formation routes may be more complex. Previous reports indicated that the photochlorination of organic compounds in saline water was initiated by the attack of chlorine radicals that originate from the $\bullet \mathrm{OH}$ scavenging of halides. In many cases, a lower $\mathrm{pH}$ facilitated the formation of chlorine radicals, resulting in the formation of more chlorinated organic compounds. However, the present research found that singlet oxygen, not - $\mathrm{OH}$, was the critical reactive oxygen species involved in the formation of chlorinated $\mathrm{BaP}$, and a higher $\mathrm{pH}$ enhanced the amount of 6-ClBaP formed. Chlorine radicals might be produced by the oxidation of $\mathrm{Cl}^{-}$ by $\bullet \mathrm{OH}$ in natural waters, but other substances quench them due to their nonselective nature and to the complexity of natural waters. The chlorination of BaP progressed through its excited states, which reacted with high concentrations of $\mathrm{Cl}^{-}$, thereby increasing the chlorination possibilities. Saline water (such as seawater and saline lakes) is typically neutral to alkaline, and a high $\mathrm{pH}$ is beneficial for the self-sensitive photochlorination of BaP. Therefore, it is possible that self-sensitive photochlorination is an important chlorination pathway of BaP except the chlorine radicals pathway in saline water.

\section{CRediT authorship contribution statement}

Mina Yang: Conceptualization, Methodology, Investigation, Writing - original draft. Haijing Zhang: Investigation. Fei Chang: Writing review \& editing. Xuefeng Hu: Supervision, Funding acquisition, Conceptualization, Methodology, Writing - original draft.

\section{Declaration of Competing Interest}

The authors declare that they have no known competing financial interests or personal relationships that could have appeared to influence the work reported in this paper.

\section{Acknowledgements}

Generous support from the National Natural Science Foundation of China (no. 41076040) and Shaanxi Thousand Talents Plan-Youth Program Scholars is acknowledged.

\section{Appendix A. Supporting information}

Supplementary data associated with this article can be found in the online version at doi:10.1016/j.jhazmat.2020.124445.

\section{References}

Abdulazeez, T., Lawal, 2017. Polycylic aromatic hydrocarbons. A review. Cogent Environ. Sci. 3, 1339841.

Anbar, M., Meyerstein, D., Neta, P., 1966. Reactivity of aliphatic compounds towards hydroxyl radicals. J. Chem. Soc. B Phys. Org. 742-747.

Bonneau, R., Pottier, R., Bagno, O., Joussot-Dubien, J., 1975. pH dependence of singlet oxygen production in aqueous solutions using thiazine dyes as photosensitizers. Photochem. Photobiol. 21, 159-163.

Del Carlo, M., Di Marello, M., Giuliani, M., Sergi, M., Pepe, A., Compagnone, D., 2012. Detection of benzo(a)pyrene photodegradation products using DNA electrochemical sensors. Biosens. Bioelectron. 31, 270-276.

Dewhurst, F., Kitchen, D.A., 1972. Synthesis and properties of 6-substituted benzo[a] pyrene derivatives. J. Chem. Soc. Perkin Trans. 1, 710-712.

Fasnacht, M.P., Blough, N.V., 2002. Aqueous photodegradation of polycyclic aromatic hydrocarbons. Environ. Sci. Technol. 36, 4364-4369.

Fasnacht, M.P., Blough, N.V., 2003a. Mechanisms of the aqueous photodegradation of polycyclic aromatic hydrocarbons. Environ. Sci. Technol. 37, 5767-5772.

Fasnacht, M.P., Blough, N.V., 2003b. Kinetic analysis of the photodegradation of polycyclic aromatic hydrocarbons in aqueous solution. Aquat. Sci. 65, 352-358.

Fioressi, S., Arce, R., 2003. Excited states and intermediate species of benzo[e]pyrene photolyzed in solution and adsorbed on surfaces. J. Phys. Chem. A 107, 5968-5975.

Fioressi, S., Arce, R., 2005. Photochemical transformations of benzo[e]pyrene in solution and adsorbed on silica gel and alumina surfaces. Environ. Sci. Technol. 39, 3646-3655.

Hu, X.F., Wang, X.W., Dong, L.L., Chang, F., Luo, Y.M., 2015. Aniline chlorination by in situ formed $\mathrm{Ag}-\mathrm{Cl}$ complexes under simulated solar light irradiation. Water Sci. Technol. 71 (11), 1679-1685.

Hu, X.F., Wu, L., Luo, Y.M., 2014. Photochlorination of aniline in Fe(III)/fulvic acidcontaining saline water under simulated solar light irradiation. Environ. Chem. 33, 611-616.

Jin, X., Peldszus, S., Huck, P.M., 2012. Reaction kinetics of selected micropollutants in ozonation and advanced oxidation processes. Water Res. 46 (19), 6519-6530.

Juhasz, A.L., Naidu, R., 2000. Bioremediation of high molecular weight polycyclic aromatic hydrocarbons: a review of the microbial degradation of benzo[a]pyrene. Int. Biodeterior. Biodegrad. 45, 57-88.

Karunakaran, C., Dhanalakshmi, R., Manikandan, G., Gomathisankar, P., 2011. Photodegradation of carboxylic acids on $\mathrm{Al}_{2} \mathrm{O}_{3}$ and $\mathrm{SiO}_{2}$ nanoparticles. Indian $\mathrm{J}$. Chem. 50, 163-170.

Kot-Wasik, A., Dabrowska, D., Namiesnik, J., 2004. Photodegradation and biodegradation study of benzo[a]pyrene in different liquid media. J. Photochem. Photobiol. A 168, 109-115.

Lawal, A.T., 2017. Polycyclic aromatic hydrocarbons. A review. Cogent Environ. Sci. 3, 1339841.

Liu, H., Zhao, H., Quan, X., Zhang, Y., Chen, S., 2009. Formation of chlorinated intermediate from bisphenol A in surface saline water under simulated solar light irradiation. Environ. Sci. Technol. 43, 7712-7717.

Luo, L., Lai, X., Chen, B., lin, L., Fang, L., Tam, N.F.Y., Luan, T., 2015. Chlorophyll catalyse the phototransformation of carcinogenic benzo[a]pyrene in water. Sci. Rep. 5, 12776.

Mai, L., Bao, L.J., Shi, L., Liu, L.Y., Zeng, E.Y., 2018. Polycyclic aromatic hydrocarbons affiliated with microplastics in surface waters of Bohai and Huanghai Seas, China. Environ. Pollut. 241, 834-840.

Ohura, T., 2007. Environmental behavior, sources, and effects of chlorinated polycyclic aromatic hydrocarbons. Sci. World J. 2007 (7), 372-380.

Ohura, T., Amagai, T., Makino, M., 2008. Behavior and prediction of photochemical degradation of chlorinated polycyclic aromatic hydrocarbons in cyclohexane. Chemosphere 70, 2110-2117.

Ohura, T., Miwa, M., 2016. Photochlorination of polycyclic aromatic hydrocarbons in acidic brine solution. Bull. Environ. Contam. Toxicol. 96, 524-529.

Parker, K.M., Mitch, W.A., 2016. Halogen radicals contribute to photooxidation in coastal and estuarine waters. Proc. Natl. Acad. Sci. USA 113, 5868-5873.

Remucal, C.K., Manley, D., 2016. Emerging investigators series: the efficacy of chlorine photolysis as an advanced oxidation process for drinking water treatment. Environ. Sci. Water Res. Technol. 2, 565-579.

Sanches, S., Leitão, C., Penetra, A., Cardoso, V.V., Ferreira, E., Benoliel, M.J., Barreto Crespo, M.T., Pereira, V.J., 2011. Direct photolysis of polycyclic aromatic hydrocarbons in drinking water sources. J. Hazard. Mater. 192, 1458-1465.

Sankoda, K., Kuribayashi, T., Nomiyama, K., Shinohara, R., 2013. Occurrence and source of chlorinated polycyclic aromatic hydrocarbons (Cl-PAHs) in tidal flats of the Ariake Bay, Japan. Environ. Sci. Technol. 47, 7037-7044. 
Sankoda, K., Nomiyama, K., Yonehara, T., Kuribayashi, T., Shinohara, R., 2012. Evidence for in situ production of chlorinated polycyclic aromatic hydrocarbons on tidal flats: environmental monitoring and laboratory scale experiment. Chemosphere 88, 542-547.

Schweitzer, C., Schmidt, R., 2003. Physical mechanisms of generation and deactivation of singlet oxygen. Chem. Rev. 103, 1685-1757.

Stathis, A., 2018. Photolysis Kinetics of Aromatic Pollutants in Liquid and Solid Environmental Condensed Phases. Syracuse University Dissertations.

Sun, J., Zeng, H., Ni, H., 2013. Halogenated polycyclic aromatic hydrocarbons in the environment. Chemosphere 90, 1751-1759.

Tambekar, D.H., Raut, N.S., Dhundale, V.R., 2013. Partial characterization and optimization of alkaline amaylase production by Bacillus circulans from Lonar Lake. Biosci. Discov. Int. J. Life Sci. 4, 202-207.

Teranishi, M., Toyooka, T., Ohura, T., Masuda, S., Ibuki, Y., 2010. Benzo[a]pyrene exposed to solar-simulated light inhibits apoptosis and augments carcinogenicity. Chem. Biol. Interact. 185, 4-11.
Vione, D., Maurino, V., Minero, C., Calza, P., Pellizzetti, E., 2005. Phenol chlorination and photochlorination in the presence of chloride ions in homogeneous aqueous solution. Environ. Sci. Technol. 39, 5066-5075.

Wang, X.W., Hu, X.F., Zhang, H., Chang, F., Luo, Y.M., 2015. Photolysis kinetics, mechanisms and pathways of tetrabromobisphenol A in water under simulated solar light irradiation. Environ. Sci. Technol. 49 (11), 6683-6690.

Wu, L., Hu, X.F., 2012. Photochlorination of aniline in $\mathrm{Fe}^{3+}$-containing saline water under simulated solar light irradiation. Environ. Chem. 9, 558-563.

Xia, X.H., Li, G.C., Yang, Z.F., Chen, Y.M., Huang, G.H., 2009. Effects of fulvic acid concentration and origin on photodegradation of polycyclic aromatic hydrocarbons in aqueous solution: importance of active oxygen. Environ. Pollut. 157, 1352-1359.

Yang, Z.Y., Shah, K., Laforest, S., Hollebone, B.P., Situ, J., Crevier, C., Lambert, P., Brown, C.E., Yang, C., 2020. Occurrence and weathering of petroleum hydrocarbons deposited on the shoreline of the North Saskatchewan River from the 2016 Husky oil spill. Environ. Pollut. 258, 113769.

Zhang, K., Jiang, B., Wang, J.Z., Guang, Y.F., Zeng, E.Y., 2012. Polycyclic aromatic hydrocarbons in upstream riverine runoff of the Pearl River Delta, China: an assessment of regional input sources. Environ. Pollut. 167, 78-84. 